\title{
Assessment of the viscosity of the pulmonary artery wall
}

\author{
Z. Visontai*, Z. Lénárd*, K. Karlocai**, M. Kollai*
}

Assessment of the viscosity of the pulmonary artery wall. Z. Visontai, Z. Lénárd, K. Karlocai, M. Kollai. (C) ERS Journals Ltd 2000.

ABSTRACT: Large artery wall viscosity reduces the efficiency of heart/vessel coupling. The aim of the present study was to assess pulmonary artery wall viscosity through comparison of the static $\left(D_{\text {st }}\right)$ and dynamic distensibility $\left(D_{\text {dyn }}\right)$ of the vessel wall.

Right pulmonary artery pressure and diameter was measured in 13 patients and eight healthy volunteers. $D$ dyn was calculated as the relative change in end-diastolic diameter induced by the pressure pulse, and $D_{\text {st }}$ as the relative change in mean diameter induced by the change in mean pressure during steady-state exercise.

$D$ st did not differ significantly from $D$ dyn (mean $\pm S D$ 22.8 \pm 19.2 versus $21.0 \pm 18.310^{-3}$ $\mathrm{mmHg}^{-1}$ ), as tested by paired t-test and analysis of covariance, with age as covariant. End-diastolic diameter increased, whereas $D$ st and $D$ dyn decreased as a function of age $(\mathrm{r}=-\mathbf{0 . 6 9}$ and $\mathbf{- 0 . 6 7}$, respectively; $\mathrm{p}<\mathbf{0 . 0 1}$ for both). Ddyn did not change from rest to exercise in spite of a $23 \pm 16$-beats min $^{-1}$ increase in cardiac frequency.

Pulmonary artery wall viscosity was negligible and no increase in wall viscosity occurred during cardioacceleration.

Eur Respir J 2000; 16: 1134-1141.

\begin{abstract}
*Clinical Research Dept and Second Institute of Physiology, Semmelweis University, and $* *$ National Korányi Institute of Pulmonology, Budapest, Hungary.
\end{abstract}

Correspondence: M. Kollai, II. Institute of Physiology, Semmelweis University, Ulloi ut 78/a, Budapest, 1082 Hungary. Fax: 36 13343162

Keywords: Age, exercise, static and dynamic distensibility, ultrasound, vessel wall tracking

Received: June 62000

Accepted after revision July 192000

This work was supported by the Hungarian National Scientific Research Fund Grant OTKA-29470 and the Ministry of Welfare Grant ETT-471/96.
The arterial wall responds to stress through both elastic and viscous behaviour, the former being related to the elastin and the latter to the collagen and smooth muscle content of the vessel wall $[1,2]$. During systole, the elastic behaviour of the arterial wall allows its diameter to increase proportionally to pressure; in the case of a purely elastic arterial wall, the total amount of energy stored would be released during diastole. In reality, however, part of the energy that corresponds to viscous deformation is dissipated within the arterial wall. Wall viscosity reduces the efficiency of heart/vessel coupling, and may place extra load on the ventricle [3].

Wall viscosity is responsible for the difference that exists between the static $(D$ st) and dynamic distensibility ( $D$ dyn) of a given vessel $[1,2,4,5]$. Under static conditions, the change in diameter in response to a given change in distending pressure is determined only by the elastic properties of the vessel wall. Under dynamic conditions, however, when changes in pressure are pulsatile and the time available for distension is limited, wall viscosity impedes distension, resulting in less change in diameter for the same change in pressure [6]. The greater the wall viscosity, the greater the difference between $D$ st and $D$ dyn. $D$ st has been found to be considerably higher than $D$ dyn in systemic arteries, the difference being accounted for by wall viscosity $[1,2,4,5]$.

Information on pulmonary artery wall viscosity is limited and controversial. In the perfused dog lungs, the slope of the static curve relating volume to pressure (i.e. lung compliance) was found to be 1.5 times steeper than that of the dynamic curve [7], indicating considerable vessel wall viscosity. In humans, no direct comparison of $D_{\text {st }}$ and $D$ dyn of the pulmonary artery has been made, but the close similarity of pressure and diameter curves recorded from the pulmonary artery has been taken as a sign of low vessel wall viscosity [8]. The age dependence of pulmonary arterial wall distensibility is another controversial issue. Although in vitro studies have shown that the pulmonary arterial wall stiffens with age $[9,10]$, in vivo studies have produced equivocal results; a negative correlation between pulmonary compliance and age was reported in one study [11] but no such relation was found in another [12].

In view of the above uncertainties, the relationship between $D$ st and $D$ dyn of the right main pulmonary artery and its age dependence was studied. Ddyn was determined from the pressure/diameter relationship during the cardiac cycle, whereas static (or, rather, quasistatic) distensibility was determined using changes in mean pulmonary artery pressure (MPAP) and diameter during physical exercise.

\section{Material and methods}

The study population consisted of 21 subjects, 13 patients and eight healthy volunteers, selected from a larger population of 50 subjects. Originally these 50 subjects had volunteered to participate in a study designed to investigate the effect of nitric oxide inhalation on pulmonary arterial pressure. This protocol included the use of Millar catheter for pressure recording. The opportunity to use noninvasive wall-tracking echo equipment after the Millar catheter was introduced but before NO inhalation started was given. Subjects for the present project were selected on the basis that right pulmonary artery diameter and distension could be measured using the 
vessel wall-tracking method, as discussed later. Six females and seven males (34-82 yrs) were recruited from among patients undergoing electrophysiological investigation at the Department of Cardiology of the National Korányi Institute of Pulmonology. All of them were free of clinical symptoms of pulmonary hypertension or lung disease. Their cardiac diagnoses were as follows: cardiomyopathy (five patients), aortic stenosis and insufficiency (four), mitral insufficiency (four), tricuspid insufficiency (three) and status after myocardial infarct (four). The mean time interval between myocardial infarction and the present study was six yrs. All patients were in sinus rhythm and breathing spontaneously during the study. Eight healthy volunteers (four females and four males; $21-$ $25 \mathrm{yrs}$ ) were also examined using the same protocol. They were recruited from among the staff of the Semmelweis Medical University and medical students. These subjects were free of clinical evidence of pulmonary hypertension or coronary artery, valvular heart or lung diseases. All subjects gave written informed consent to participate in the study, which was approved by the Ethical Committee of the Scientific Health Council, Budapest, Hungary.

Right heart catheterization and pulmonary artery pressure measurement

All subjects underwent right heart catheterization without premedication in the supine position. A catheter tip micromanometer (Millar SPC-340; size 4 F, Houston, TX, USA) was introduced into the right main branch of the pulmonary artery under fluoroscopic guidance, using standard procedures. Measurements were referred to as zero level at $5 \mathrm{~cm}$ below the sternal angle. All catheterization was carried out by the same operator, and no complications were observed during the procedure.

\section{Ultrasonographic measurements}

Pulmonary artery diameter and distensions were measured by means of ultrasonography. Measurement of pulmonary artery dimensions was made $\geq 15$ min after catheterization. The ultrasound device consisted of a vessel wall-tracking system (WTS) combined with a conventional ultrasound scanner (Scanner 200; Pie Medical, Maastricht, the Netherlands), which has previously been described in detail $[13,14]$. In brief, the pulmonary artery was visualized, at first in two-dimensional mode, and then the ultrasound system was switched to M mode and ultrasound was emitted and received along a selected $\mathrm{M}$ line visable on the echo-screen. The WTS is a data acquisition system capable of capturing the received and amplified radio frequency (RF) signals. After completion of data acquisition, the data were transferred to a personal computer. The first line acquired was then presented graphically on a display, allowing manual identification of the anterior and posterior boundaries by placing two markers that represent the sample windows for data processing. In order to extract the change in position of either the anterior or the posterior wall, the approach based on the cross-correlation model for corresponding segments of subsequent RF lines was applied. In order to ensure that the signals returned by the same structure were always considered, the position of the sample windows was adjusted according to the observed displacements (tracking window). The difference between the displacements of signals of the anterior and posterior walls yielded the change in diameter as a function of time, i.e. the distension waveform. The minimum distance between the wall signals was defined as the diastolic diameter. Imaging of the right main branch of the pulmonary artery was performed from the suprasternal notch, using a $3.5-\mathrm{MHz}$ mechanical sector transducer, with the subjects in the supine position. A standard limb lead electrocardiogram (ECG) was recorded to obtain R-waves that served as a trigger for activation of the WTS algorithm. Respiration was monitored using inductive plethysmography (Respitrace; Ambulatory Monitoring, Inc, Ardsley, NY, USA).

Construction of pressure/diameter loops was carried out using computer software that plots the diameter signal against the pressure signal during the cardiac cycle. Prior to plotting, the two signals need to be synchronized because the hysteresis loop area varies depending on the phase lag between the diameter and pressure signals. Synchronization was performed by aligning the upshoot of the diameter and pressure pulses according to their steepest slopes. In most cases, not much alignment was necessary because pressure and diameter was measured at almost the same site along the right pulmonary artery.

\section{Reproducibility of measurements of dimensions}

At least 10-15 successful recordings were obtained during each recording session; repeated measurements were used to assess intrasession intraobserver variability. Two complete series of recordings were obtained in eight subjects by two different observers in order to assess interobserver variability. Measurements were repeated in the same eight subjects within 2 weeks by the same observers, to assess intersession variability. In order to assess the reproducibility of measurements, the coefficient of variation was calculated. The intrasession, interobserver and intersession reproducibility of the measurements of diameter and distension are given in table 1. By comparison, Kool et al. [15] measured pulsatile distension of the common carotid artery, using the WTS with a 7.5$\mathrm{MHz}$ transducer, and reported 7.9 $\pm 1.6,9.2 \pm 0.9$ and $11.3 \pm 2.6 \%$ (mean $\pm \mathrm{SEM})$ for intraobserver intrasession,

Table 1. - Coefficient of variation (reproducibility) of dimension measurements

\begin{tabular}{lccc}
\hline & $\begin{array}{c}\text { Intrasession } \\
\text { intraobserver }\end{array}$ & $\begin{array}{c}\text { Intrasession } \\
\text { interobserver }\end{array}$ & $\begin{array}{c}\text { Intersession } \\
\text { intraobserver }\end{array}$ \\
\hline Control & & & \\
Subjects $\mathrm{n}$ & 16 & 8 & 8 \\
$\mathrm{~d}$ & $4.3 \pm 1.9$ & $4.8 \pm 1.6$ & $6.4 \pm 3.1$ \\
$\Delta \mathrm{d}$ & $9.6 \pm 3.9$ & $8.5 \pm 3.8$ & $15.0 \pm 4.3$ \\
Exercise & & & \\
Subjects $\mathrm{n}$ & 19 & 8 & 8 \\
$\mathrm{~d}$ & $4.8 \pm 2.1$ & $6.2 \pm 2.3$ & $7.0 \pm 2.7$ \\
$\Delta \mathrm{d}$ & $13.8 \pm 4.8$ & $14.7 \pm 4.6$ & $17.7 \pm 5.4$ \\
\hline
\end{tabular}

Data are presented as mean \pm SD. d: end-diastolic diameter of right main pulmonary artery; $\Delta \mathrm{d}$ : change in diameter of right main pulmonary artery from end diastole to peak systole. 
intraobserver intersession and interobserver intrasession variabilities.

\section{Protocol}

Subjects were instrumented (electrodes mounted, catheter introduced), rested for $15 \mathrm{~min}$ in the supine position and then a 5-min recording of pulmonary artery diameter and pressure, together with ECG and respiration, made. The subjects then performed exercise in the supine position. They had their legs elevated and feet positioned on a bicycle ergometer (Jaeger ER-900L, Würzberg, Germany). The load was increased until exercise induced an increase in MPAP of 5-15 $\mathrm{mmHg}$, depending upon age and pulmonary distensibility. The applied load ranged 75-200 $\mathrm{W}$, and resulted in an increase in MPAP of $8 \pm 5 \mathrm{mmHg}$ and in cardiac frequency of $23 \pm 16$ beats $\mathrm{min}^{-1}$ (mean \pm SD). Steady state was verified by stable cardiac frequency and pulmonary arterial pressure. The load was maintained at the steady-state level for $5 \mathrm{~min}$, during which time the above variables were continuously recorded. The ultrasound transducer was kept in the same position throughout the recording period.

\section{Data analysis}

The Ddyn of the pulmonary artery was calculated as $2 \Delta \mathrm{d} / \mathrm{d} \Delta P$, where $\mathrm{d}$ is end-diastolic diameter, $\Delta \mathrm{d}$ change in diameter from end diastole to peak systole and $\Delta P$ pulse pressure. $\mathrm{d}, \Delta \mathrm{D}$ and $\Delta P$ were measured and $D$ dyn calculated on a beat-by-beat basis and averaged. $D$ st was defined as $2 \Delta \mathrm{d} /(\mathrm{d} \Delta \mathrm{MPAP})$, where $\mathrm{d}$ mean diameter averaged for the pulse, and $\Delta \mathrm{d}$ is change. In each subject, 10-15 end-expiratory cardiac cycles were used for analysis both at rest and during steady exercise.

\section{Statistical analysis}

Data are presented as mean \pm SD. Differences between $D_{\text {st }}$ and $D$ dyn were tested by paired t-test and analysis of covariance, using age as covariant. Relationships between distensibility parameters and other variables (age, MPAP and cardiac frequency) were evaluated by simple and multiple linear regression analyses. Statistical analyses were performed using the StatSoft (Tulsa, OK, USA), STATISTICA for Windows, Release 5.0, package.

\section{Results}

Representative pressure and diameter curves for one cardiac cycle recorded from the right main branch of the pulmonary artery in a young healthy subject are presented in figure 1 . Figure $1 \mathrm{c}$ shows the pressure/diameter hysteresis loop for this cycle. The pressure/diameter relationship appears to be linear in the diastolic/systolic pressure range. The hysteresis loop is narrow, with a small area, indicating low wall viscosity. Diastolic/systolic pulmonary arterial pressure/diameter relations for a younger and an older subject are compared in figure 2 . In the younger subject, end-diastolic diameter was smaller at
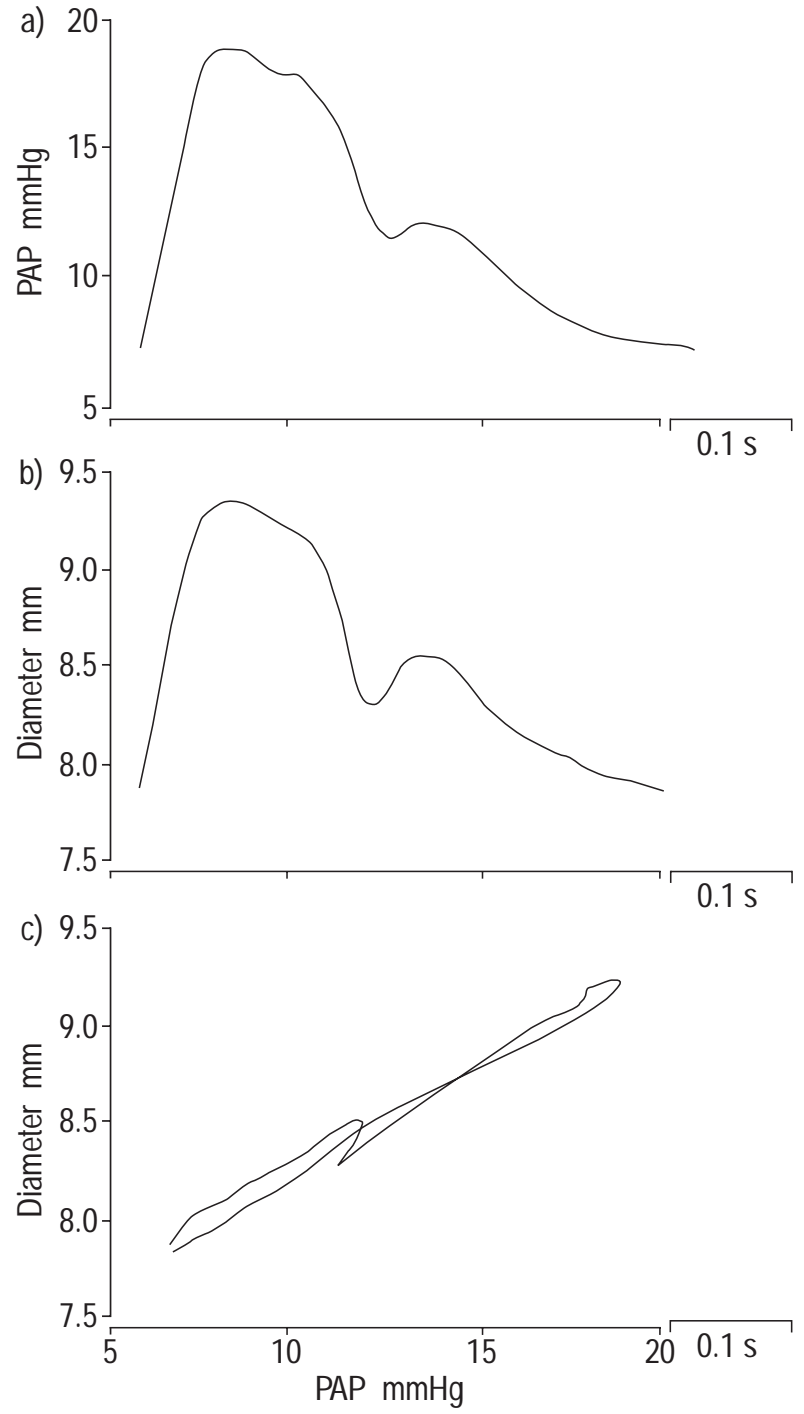

Fig. 1. - Representative a) pressure; and b) diameter recordings from the right main branch of the pulmonary artery in a young healthy subject. c) Pressure/diameter hysteresis loop (constructed from a and b). PAP: pulmonary artery pressure.

rest and dilated more in response to a smaller pulse pressure than in the older subject. In response to the rise in pressure induced by exercise, the pressure/diameter relations shifted to the right, approximately along the axes of the control relations. The slope of the diastolic/ systolic pressure/diameter relation reflects $D$ dyn, whereas the slopes of the lines connecting mean pressure and diameter indicate $D$ st. $D$ dyn and $D$ st did not seem to differ considerably in either subject. In systemic arteries, the pressure/diameter relation was found to shift markedly upwards during pressure responses, indicating significantly higher $D$ st than $D$ dyn $[1,2,5]$. The clinical characteristics of all the subjects are given in table 2 .

In all the present subjects, physical exercise produced a significant increase in MPAP $(8 \pm 5 \mathrm{mmHg})$, but did not lead to an upward shift of the pressure/diameter relation, i.e. $D$ st did not differ significantly from $D$ dyn $(22.8 \pm 19.2$ versus $21.0 \pm 18.310^{-3} \mathrm{mmHg}^{-1}$ ). Also, Ddyn did not change significantly between rest and exercise $(21.0 \pm 18.3$ versus 


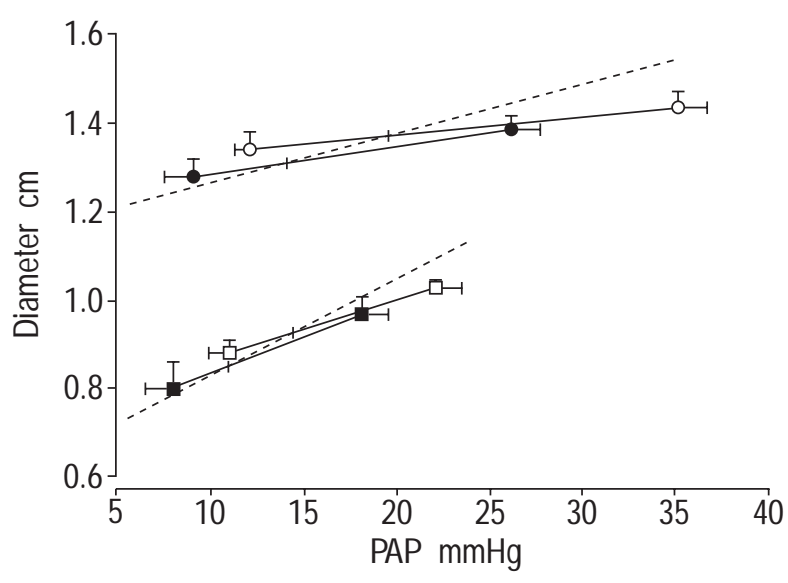

Fig. 2. - Representative diastolic/systolic pulmonary artery pressure (PAP) and diameter data for a 21 -yr-old (square symbols) and a 44-yrold (round symbols) subject. ( $\bigcirc, \square$ : rest; $\bigcirc, \square$ : exercise; - - - : connecting mean pressure and diameter). Data are presented as mean $\pm \mathrm{SD}$ $(\mathrm{n}=15)$.

$\left.17.7 \pm 11.910^{-3} \mathrm{mmHg}^{-1}\right)$. The difference between $D$ st and $D$ dyn did not exhibit any trend when plotted against mean distensibility, and the limit of agreement calculated according to the method of BLAND and AltMAn [16] amounted to $1.9 \pm 11.610^{-3} \mathrm{mmHg}^{-1}$ (mean difference $\pm 2 \mathrm{SD}$ ). $D$ st was proportional to $D$ dyn across subjects, as shown by linear regression analysis $(\mathrm{r}=0.95, \mathrm{p}<0.001)$ (fig. 3), with the regression line falling almost on the line of identity.

The end-diastolic diameter of the right pulmonary artery increased $(r=0.77, p<0.005)$, whereas distension with the pressure pulse tended to decrease, with age ( $\mathrm{r}=-0.4$, NS), resulting in a significant reduction in $D$ dyn with increasing age $(\mathrm{r}=-0.67, \mathrm{p}<0.01)$. Dst exhibited similar reduction with age $(r=-0.69, p<0.01)$, and the age relations of $D$ st and $D$ dyn did not differ significantly when tested by analysis of covariance, using age as covariant (fig. 4).

Resting MPAP ranged $11-42 \mathrm{mmHg}$, and was $>20$ $\mathrm{mmHg}$ in six subjects (table 2). It is of note that none of these subjects had any complaints or symptoms that were related to lung function or pulmonary circulation prior to the study. In accordance with earlier findings [17, 18], pulmonary artery distensibility was lower in hypertensive subjects as compared to the remaining subjects with normal pulmonary pressure $(8.5 \pm 5.5$ versus $28.5 \pm 19.8$ $10^{-3} \mathrm{mmHg}^{-1}$ for $D$ st and $7.4 \pm 3.5$ versus $26.5 \pm 19.110^{-3}$ $\mathrm{mmHg}^{-1}$ for $D$ dyn). When pulmonary artery distensibility was related using forward stepwise multiple regression to both age and MPAP, the contribution of MPAP approached significance (table 3 ). Conversely neither $D$ st, nor $D$ dyn was related to resting cardiac frequency.

\section{Discussion}

The present study is the first in which the issue of pulmonary artery wall viscosity has been directly addressed. It was found that $D$ st and $D$ dyn did not differ to any significant extent in humans, regardless of age. This finding implies that pulmonary artery wall viscosity, determined mainly by collagen and smooth muscle content, is relatively unimportant and that elastic elements in the vessel wall are predominantly responsible for its physical behaviour. The elastic pulmonary arterial tree stores the potential energy generated by the heart during systole and restores it during diastole, maintaining adequately high driving pressure at the periphery [6]. The difference between the stored and restored quantities of energy is dissipated, mainly due to wall viscosity, and arterial wall viscosity is considered the main source of pressure-wave attenuation along the arterial tree [19]. The very low wall viscosity of proximal pulmonary arteries, suggested by the present data, results in efficient heart/ vessel coupling both at rest and during cardioacceleration.

\section{Measurement of pulmonary artery dimensions with the ultrasound wall-tracking system}

In earlier studies, this ultrasound technique was used to investigate superficial arteries $[13,14]$. The short distance between ultrasound source and target object allowed the use of high-frequency transducers $(7.5-10 \mathrm{MHz}$ ), yielding high spatial resolution $(5-200 \mu \mathrm{m})$. Since the right pulmonary artery is situated $5-8 \mathrm{~cm}$ below the suprasternal notch, a $3.5-\mathrm{MHz}$ transducer with a spatial resolution of $\sim 0.5 \mathrm{~mm}$ had to be used in the present study. In this way, the pulmonary artery diameter was determined to within $\sim 1 \mathrm{~mm}$. The conditions for measuring distension with the WTS, however, are far more favourable. Once the vessel wall has been identified, and a sample window positioned within the RF signal, the WTS algorithm tracks wall displacements with great accuracy. Hoeks et al. [13] demonstrated in vitro that, with a $7.5-\mathrm{MHz}$ transducer, this technique can resolve diameter changes of $<1 \mu \mathrm{m}$. In the present study, a 3.5$\mathrm{MHz}$ transducer was used in vivo. KAWASAKI et al. [20] and LANNE et al. [21], using wall-tracking echo systems in vivo with $3.5-\mathrm{MHz}$ transducers, reported 5 and $8 \mu \mathrm{m}$ as the smallest detectable movement.

Because the present study is the first in which the WTS has been used on the pulmonary artery, the technique needs validation in this new setting. PAz et al. [22] used magnetic resonance imaging to study right pulmonary artery wall distensibility in nine healthy volunteers with a mean age of 42.9 yrs (range 28-49 yrs), and reported a mean \pm SD pulsatile change in cross-sectional area of $21.5 \pm 11.2 \%$. In a subgroup of nine of the present subjects of similar age (mean 42.1 yrs; range 23-44 yrs), the corresponding value was $20.0 \pm 9.8 \%$. BOGREN et al. [17] studied the main pulmonary artery using MRI and reported a pulsatile change in cross-sectional area of $23 \%$ (range $17-30 \%$ ). In earlier work on the aortic arch, in which the wall-tracking technique was used with a 3.5$\mathrm{MHz}$ transducer, the recorded data were in agreement with data in the literature obtained by various techniques (angiology, mechanical and ultrasonic calliper, and magnetic resonance imaging) [23].

The WTS technique has been used previously to measure aortic arch diameter and distension, failing in only $10 \%$ of the subjects studied [23]. In the present study, the success rate for measuring pulmonary artery dimensions was much lower $(<50 \%)$. Two types of difficulty were encountered. In some cases, mainly in older subjects, the quality of the M-mode image was simply not satisfactory for WTS analysis. In other cases, movement of the lower wall of the right pulmonary artery produced 


\begin{tabular}{|c|c|c|c|c|c|c|c|c|c|c|c|c|c|}
\hline \multirow[b]{2}{*}{$\begin{array}{l}\text { Age } \\
\text { yrs }\end{array}$} & \multicolumn{6}{|c|}{ Control } & \multicolumn{7}{|c|}{ Exercise } \\
\hline & $\begin{array}{c}\quad f \mathrm{R} \\
\text { beats } \cdot \mathrm{min}^{-1}\end{array}$ & $\begin{array}{l}\text { MPAP } \\
\mathrm{mmHg}\end{array}$ & $\begin{array}{r}\Delta P \\
\mathrm{mmHg}\end{array}$ & $\begin{array}{l}\mathrm{d} \\
\mathrm{cm}\end{array}$ & $\begin{array}{l}\Delta \mathrm{d} \\
\mathrm{cm}\end{array}$ & $\begin{array}{c}D \text { dyn } \\
10^{-3} \mathrm{mmHg}^{-1}\end{array}$ & $\begin{array}{c}\quad f \mathrm{R} \\
\text { beats. } \min ^{-1}\end{array}$ & $\begin{array}{l}\text { MPAP } \\
\text { mmHg }\end{array}$ & $\begin{array}{c}\Delta P \\
\mathrm{mmHg}\end{array}$ & $\begin{array}{l}\mathrm{d} \\
\mathrm{cm}\end{array}$ & $\begin{array}{l}\Delta \mathrm{d} \\
\mathrm{cm}\end{array}$ & $\begin{array}{c}D \text { dyn } \\
10^{-3} \mathrm{mmHg}^{-1}\end{array}$ & $\begin{array}{c}D_{\mathrm{st}} \\
10^{-3} \mathrm{mmHg}^{-1}\end{array}$ \\
\hline 21 & 60 & $11 \pm 1.0$ & $10 \pm 0.9$ & $0.80 \pm 0.04$ & $0.17 \pm 0.021$ & $44.3 \pm 4.3$ & 65 & $15 \pm 1.0$ & $11 \pm 1.0$ & $0.88 \pm 0.03$ & $0.15 \pm 0.023$ & $33.8 \pm 4.5$ & $40.7 \pm 4.3$ \\
\hline 21 & 75 & $20 \pm 1.3$ & $7 \pm 1.0$ & $0.91 \pm 0.04$ & $0.12 \pm 0.013$ & $38.6 \pm 5.2$ & 99 & $28 \pm 1.3$ & $10 \pm 1.2$ & $1.04 \pm 0.05$ & $0.21 \pm 0.024$ & $41.7 \pm 4.4$ & $42.1 \pm 4.6$ \\
\hline 21 & 65 & $13 \pm 0.6$ & $5 \pm 0.5$ & $1.06 \pm 0.04$ & $0.06 \pm 0.008$ & $27.9 \pm 3.3$ & 75 & $15 \pm 0.5$ & $5 \pm 0.4$ & $1.09 \pm 0.05$ & $0.06 \pm 0.007$ & $23.0 \pm 2.4$ & $27.8 \pm 3.5$ \\
\hline 21 & 58 & $18 \pm 0.6$ & $6 \pm 0.6$ & $1.00 \pm 0.06$ & $0.05 \pm 0.008$ & $19.6 \pm 2.4$ & 62 & $22 \pm 0.6$ & $9 \pm 0.9$ & $1.01 \pm 0.04$ & $0.08 \pm 0.008$ & $20.3 \pm 3.1$ & $14.9 \pm 1.5$ \\
\hline 23 & 80 & $17 \pm 1.0$ & $5 \pm 0.8$ & $0.78 \pm 0.04$ & $0.13 \pm 0.012$ & $66.7 \pm 6.2$ & 100 & $28 \pm 1.2$ & $10 \pm 1.0$ & $1.05 \pm 0.06$ & $0.19 \pm 0.011$ & $36.3 \pm 2.6$ & $64.0 \pm 8.1$ \\
\hline 23 & 70 & $16 \pm 0.5$ & $13 \pm 0.6$ & $0.98 \pm 0.04$ & $0.15 \pm 0.016$ & $23.6 \pm 3.4$ & 85 & $20 \pm 1.2$ & $13 \pm 1.1$ & $1.04 \pm 0.05$ & $0.16 \pm 0.023$ & $23.7 \pm 1.4$ & $29.1 \pm 3.1$ \\
\hline 24 & 80 & $18 \pm 1.1$ & $8 \pm 1.0$ & $0.88 \pm 0.04$ & $0.08 \pm 0.009$ & $25.1 \pm 1.4$ & 92 & $24 \pm 0.6$ & $8 \pm 0.7$ & $0.96 \pm 0.01$ & $0.13 \pm 0.016$ & $36.6 \pm 4.0$ & $37.0 \pm 4.0$ \\
\hline 25 & 85 & $18 \pm 1.1$ & $8 \pm 1.0$ & $0.80 \pm 0.03$ & $0.19 \pm 0.014$ & $62.5 \pm 5.8$ & 112 & $27 \pm 1.3$ & $11 \pm 1.1$ & $1.09 \pm 0.04$ & $0.13 \pm 0.015$ & $32.2 \pm 3.7$ & $69.8 \pm 8.4$ \\
\hline 34 & 80 & $39 \pm 1.2$ & $26 \pm 1.1$ & $1.03 \pm 0.05$ & $0.04 \pm 0.004$ & $3.2 \pm 0.4$ & 110 & $50 \pm 2.6$ & $27 \pm 1.5$ & $1.11 \pm 0.02$ & $0.04 \pm 0.007$ & $2.3 \pm 0.2$ & $13.9 \pm 1.6$ \\
\hline 44 & 64 & $15 \pm 1.0$ & $17 \pm 1.1$ & $1.28 \pm 0.04$ & $0.11 \pm 0.008$ & $10.2 \pm 2.1$ & 78 & $20 \pm 1.0$ & $23 \pm 1.0$ & $1.34 \pm 0.05$ & $0.10 \pm 0.014$ & $6.3 \pm 0.3$ & $15.2 \pm 1.4$ \\
\hline 45 & 105 & $28 \pm 1.3$ & $12 \pm 0.9$ & $0.99 \pm 0.01$ & $0.06 \pm 0.008$ & $10.3 \pm 2.6$ & 128 & $37 \pm 1.3$ & $16 \pm 1.0$ & $1.02 \pm 0.06$ & $0.13 \pm 0.016$ & $16.5 \pm 2.5$ & $11.0 \pm 1.9$ \\
\hline 45 & 70 & $36 \pm 1.3$ & $9 \pm 0.8$ & $1.30 \pm 0.04$ & $0.07 \pm 0.005$ & $11.9 \pm 2.0$ & 96 & $48 \pm 1.5$ & $10 \pm 1.1$ & $1.35 \pm 0.06$ & $0.08 \pm 0.012$ & $11.9 \pm 4.4$ & $7.6 \pm 1.1$ \\
\hline 46 & 60 & $16 \pm 0.9$ & $7 \pm 0.9$ & $1.18 \pm 0.03$ & $0.07 \pm 0.014$ & $18.0 \pm 1.7$ & 68 & $18 \pm 1.0$ & $8 \pm 1.0$ & $1.20 \pm 0.04$ & $0.09 \pm 0.010$ & $20.4 \pm 5.4$ & $25.0 \pm 2.8$ \\
\hline 47 & 75 & $42 \pm 2.2$ & $35 \pm 1.9$ & $1.43 \pm 0.05$ & $0.19 \pm 0.013$ & $7.6 \pm 1.1$ & 118 & $58 \pm 2.3$ & $56 \pm 2.3$ & $1.44 \pm 0.07$ & $0.22 \pm 0.021$ & $5.6 \pm 0.3$ & $1.7 \pm 0.2$ \\
\hline 52 & 75 & $19 \pm 1.1$ & $6 \pm 0.6$ & $1.56 \pm 0.08$ & $0.11 \pm 0.009$ & $25.3 \pm 3.2$ & 90 & $24 \pm 0.9$ & $8 \pm 0.9$ & $1.65 \pm 0.08$ & $0.14 \pm 0.019$ & $20.6 \pm 2.7$ & $25.0 \pm 3.1$ \\
\hline 54 & 70 & $14 \pm 1.0$ & $12 \pm 1.0$ & $1.35 \pm 0.04$ & $0.09 \pm 0.010$ & $11.5 \pm 1.2$ & 81 & $17 \pm 1.0$ & $10 \pm 0.9$ & $1.38 \pm 0.06$ & $0.10 \pm 0.015$ & $6.6 \pm 0.7$ & $14.5 \pm 1.9$ \\
\hline 56 & 70 & $19 \pm 1.0$ & $7 \pm 0.8$ & $1.27 \pm 0.03$ & $0.06 \pm 0.008$ & $14.2 \pm 1.3$ & 104 & $40 \pm 2.5$ & $8 \pm 0.7$ & $1.54 \pm 0.08$ & $0.06 \pm 0.008$ & $10.3 \pm 1.1$ & $19.9 \pm 2.1$ \\
\hline 69 & 63 & $42 \pm 2.5$ & $22 \pm 1.7$ & $1.43 \pm 0.06$ & $0.12 \pm 0.013$ & $7.6 \pm 0.8$ & 88 & $53 \pm 2.9$ & $21 \pm 2.8$ & $1.46 \pm 0.05$ & $0.10 \pm 0.011$ & $6.9 \pm 0.9$ & $2.5 \pm 0.3$ \\
\hline 73 & 78 & $27 \pm 1.3$ & $22 \pm 1.5$ & $1.38 \pm 0.04$ & $0.05 \pm 0.006$ & $3.5 \pm 0.4$ & 89 & $36 \pm 1.4$ & $25 \pm 1.2$ & $1.46 \pm 0.07$ & $0.09 \pm 0.014$ & $4.6 \pm 2.8$ & $14.3 \pm 1.5$ \\
\hline 79 & 80 & $17 \pm 1.0$ & $7 \pm 0.6$ & $1.57 \pm 0.07$ & $0.02 \pm 0.004$ & $4.9 \pm 0.5$ & 96 & $26 \pm 1.1$ & $7 \pm 0.5$ & $1.58 \pm 0.09$ & $0.04 \pm 0.007$ & $7.6 \pm 0.6$ & $1.4 \pm 0.3$ \\
\hline 82 & 55 & $18 \pm 1.1$ & $16 \pm 1.0$ & $1.14 \pm 0.06$ & $0.04 \pm 0.003$ & $4.9 \pm 0.7$ & 68 & $29 \pm 0.9$ & $20 \pm 1.0$ & $1.14 \pm 0.04$ & $0.06 \pm 0.007$ & $5.6 \pm 0.5$ & $1.6 \pm 0.2$ \\
\hline
\end{tabular}

Data are presented as mean $\pm \mathrm{SD}$. $f \mathrm{R}$ : cardiac frequency; MPAP: mean pulmonary artery pressure; $\Delta P$ : pulmonary pulse pressure; d: end-diastolic diameter of the right main pulmonary artery; $\Delta$ d: change in diameter from end diastole to peak systole; $D$ dyn: dynamic distensibility; $D$ st: static distensibility. $(1 \mathrm{mmHg}=0.133 \mathrm{kPa}$.) 


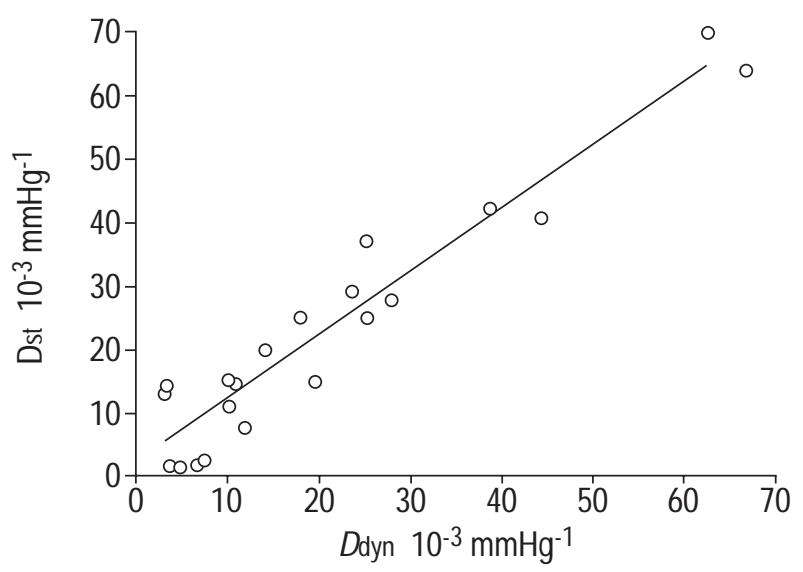

Fig. 3. - Relationship between the static $(D$ st $)$ and dynamic distensibility (Ddyn) of the pulmonary artery across subjects. $D$ st $=0.99$ $D$ dyn+1.82, $\mathrm{r}=0.95, \mathrm{p}<0.001$.

bizarre patterns. The authors suspect that the proximity of contracting cardiac chambers might have caused pulmonary artery wall movements not related to intravascular pressure. Owing to this high failure rate, the WTS method cannot be recommended for routine clinical use for the measurement of pulmonary artery distension and elastic variables.

Pulmonary artery pressure and diameter have previously been measured in one study [8]. These measurement were performed, however, during open chest surgery with the pulmonary artery exposed. It is known that surgical manipulations alter the distensibility of exposed arteries [24], and it is an open question as to what extent wall viscosity is affected during surgical procedures.

\section{Static and dynamic distensibility of the pulmonary artery}

The present data suggest that $D$ st and $D$ dyn of the pulmonary artery are not significantly different. This finding is at variance with animal data reported by LINEHAM et al. [7], who found the slope of the static pressure/ volume curve of the perfused lung to be 1.5 times greater than that of the dynamic curve. The reason for this

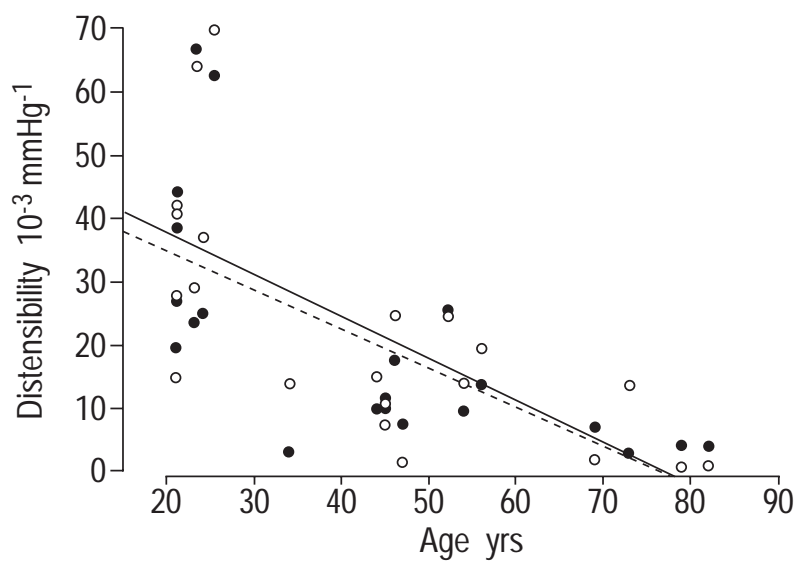

Fig. 4. - Linear regression of static ( $D$ st; $\bigcirc$; - - -) and dynamic distensibility $(D$ dyn; $0 ;-)$ of the pulmonary artery against age. $D_{\mathrm{st}}=-$ 0.64 age $+50.72, \mathrm{r}=0.69, \mathrm{p}<0.01 ; D$ dyn=-0.60 age $+46.00, \mathrm{r}=0.67, \mathrm{p}<0.01$.
Table 3. - Forward stepwise regression of factors influencing pulmonary artery distensibility

\begin{tabular}{llccrl}
\hline $\begin{array}{l}\text { Dependent } \\
\text { variable }\end{array}$ & $\begin{array}{l}\text { Independent } \\
\text { variable }\end{array}$ & $\mathrm{B}$ & $\Delta R^{2}$ & $\mathrm{~F}$ & $\mathrm{p}$-value* \\
\hline$D$ dyn & Age yrs & -0.59 & 0.44 & 15.45 & 0.003 \\
& MPAP mmHg & -0.28 & 0.07 & 2.79 & 0.11 \\
$D$ st & Age yrs & -0.56 & 0.47 & 17.03 & 0.005 \\
& MPAP mmHg & -0.35 & 0.08 & 3.55 & 0.07 \\
\hline
\end{tabular}

*: for obtaining an $\mathrm{F}$ value greater than the given $\mathrm{F} ; \mathrm{F}$ to entry=1. B: standardized regression coefficient; $\Delta R^{2}$ : amount of additional variability explained by the given variable; F: Fstatistic for testing $\mathrm{R}=0$; Fall: $\mathrm{F}$-statistic for testing all $\mathrm{R}=0$; $D$ dyn: dynamic distensibility; $D$ st: static distensibility; MPAP: mean pulmonary artery pressure. $D$ dyn: $\mathrm{R}^{2}=0.52$, Fall $=9.85, \mathrm{p}<0.001$; $D$ st: $\mathrm{R}^{2}=0.59$, Fall $=8.17, \mathrm{p}<0.001$.

discrepancy is not clear, but methodological differences might be responsible. In the study of LinEHAM et al. [7], the pulmonary veins were occluded at constant arterial inflow rate and the dynamic and static elastic behaviour of the whole pulmonary circulatory system was derived from analysis of arterial and venous pressure response curves. It is not clear which segments of the pulmonary vasculature, and to what extent, were responsible for the observed changes. In the present study, physiological forcings were used and the elastic behaviour of an identified segment of the right pulmonary artery determined. The present results are in line with data obtained from patients undergoing open-heart surgery, in whom the pressure and diameter of the main pulmonary artery was measured locally by invasive means [8]. The shape of the pressure and diameter curves were strikingly similar, indicating no phase differences between the two signals, i.e. no significant effect of vessel wall viscosity. In the ascending aorta, the similarity between the contours of pressure and diameter curves obtained using the same technique was considerably less [25]. The relationship between instantaneous distending pressure and the diameter of the pulmonary artery was also studied in the thoracotomized dog [26]. The pressure/diameter hysteresis loop was found to be narrow, and its area remained small after noradrenalin administration, indicating negligible viscous resistance of the vessel wall, even after smooth muscle activation.

\section{Effect of cardiac frequency}

The distensibility of systemic arteries is a frequencydependent phenomenon due to viscoelasticity of the arterial wall $[1,2,6]$. Pulmonary artery elastic parameters were shown to be independent of pulsatile frequency, i.e. of cardiac frequency in in vivo studies or of the frequency of applied pressure forcings in in vitro experiments $[18,27]$. The present results corroborate these earlier findings. The cardiac frequency of the present subjects during exercise increased by $\sim 25 \%$, but this increase in cardiac frequency was not accompanied by a significant reduction in $D$ dyn. In addition, cardiac frequency did not appear to be a significant predictor of either $D$ dyn or $D$ st of the pulmonary artery when studied in a multiple regression design. The independence of distensibility of the rate of distension indicates low wall viscosity. 


\section{Effect of exercise}

Smooth muscle tone in the pulmonary artery is likely to be affected by exercise, which might result in altered wall elasticity and viscosity. Exercise is associated with sympathoadrenergic activation and increased plasma catecholamine levels. Catecholamines evoke smooth muscle contraction in the pulmonary arterial wall in vitro, and affect wall elasticity [28]. During exercise, however, when blood pressure is elevated, the change in diameter reflects the net effect of passive dilatatory forces and active smooth muscle contraction. How the balance is set in the pulmonary artery during exercise is not known. Data available from humans for the also elastic-type carotid artery suggest the dominance of passive dilatatory forces during pressor responses induced by vasoactive drugs [14] or physical exercise [29]. Similarly, it has been concluded that carotid artery diameter is determined predominantly by passive mechanisms, since no differences were observed in pressure/diameter relations during pressor responses produced by different vasoconstrictor drugs in the rat [1]. Were smooth muscle activation during pressor responses to tend to reduce $D$ st, then it would also reduce the difference between $D$ st and $D$ dyn, i.e. wall viscosity. Recently, however, it was shown that sustained changes in smooth muscle tone did not influence aortic wall viscosity [30].

\section{Influence of age}

Systemic arteries are known to become stiffer with increasing age [31]. A similar age-related decline in pulmonary artery distensibility was demonstrated in the present study. The predictive power of the age relation may appear to be low $\left(r^{2}=0.5\right)$, due to the great variation in distensibility at younger ages. However, $\mathrm{r}^{2}=0.5$ means that $50 \%$ of the difference in distensibility was accounted for by age. The present data are in line with a number of earlier observations, obtained both in vitro and in vivo [9, 10]. PASIERSKI et al. [12], however, employing the conventional ultrasound M-mode technique for measuring vessel diameter, found that the elastic modulus (the ratio of pulmonary arterial pressure to vessel wall strain) was independent of age, and was related only to pulmonary arterial pressure. It is a common finding that pulmonary artery distensibility is reduced in patients with pulmonary hypertension $[17,18]$. In the study of PASIERSKI et al. [12] MPAP ranged 15-56 mmHg, with most of the patients being hypertensive, suggesting that the effect of age on pulmonary artery stiffness was overwhelmed by the dominating influence of pulmonary artery pressure.

\section{Effect of cardiac pathology}

All of the present patients had cardiac conditions, and none suffered from pulmonary hypertension or lung disease. Nevertheless, in cardiac patients with myocardial infarction or cardiac failure, the plasma catecholamine level is elevated and the renin/angiotensin system activated. In vitro studies show that catecholamines evoke smooth muscle contraction in the pulmonary arterial wall
[28] and angiotensin II induces hypertrophy of pulmonary artery myocytes [32]. It has been suggested that active contraction of vascular smooth muscle may change the viscosity as well as the elasticity of the arterial wall [33]. More recently, however, BAUER et al. [28] reported that, in contrast with the static modulus, the dynamic elastic modulus and the coefficient of wall viscosity were virtually uninfluenced by smooth muscle tone, when various arterial segments were studied in vitro under the condition of activation induced by noradrenalin and relaxation induced by papaverine. BOUTOUYRIE et al. [30] confirmed in vivo that wall viscosity was not influenced by smooth muscle tone. The above observations were made on systemic arteries, and it remains to be established whether pulmonary arteries behave in a similar fashion. The present data suggest that this may be the case, since dynamic and static distensibilities were similar in different subjects, irrespective of their clinical diagnosis, i.e. of possible differences in plasma catecholamine and angiotensin II level.

Acknowledgements. The authors acknowledge the skilled technical assistance of G. Jokkel, G. Kovacs and B. Mersich and the secretarial help of M. Mile.

\section{References}

1. Glaser E, Lacolley P, Boutouyrie P, et al. Dynamic versus static compliance of the carotid artery in living WistarKyoto rats. J Vasc Res 1995; 32: 254-265.

2. Lichtenstein O, Safar ME, Mathieu E, Poitevin P, Levy BI. Static and dynamic mechanical properties of the carotid artery from normotensive and hypertensive rats. Hypertension 1998; 32: 346-350.

3. Nichols WW, O'Rourke M. MacDonald's blood flow in arteries. London, Edward Arnold, 1990; pp. 398-419.

4. Boutouyrie $\mathrm{P}$, Bézie I, Lacolley $\mathrm{P}$, et al. In vivo/in vitro comparison of rat abdominal aorta wall viscosity. Arterioscler Thromb Vasc Biol 1997; 17: 1346-1355.

5. Lénárd Zs, Fülöp D, Visontai Zs, Jokkel G, Reneman R, Kollai M. Static versus dynamic distensibility of the carotid artery in humans. J Vasc Res 2000; 37: 103-111.

6. Bergel DW. The dynamic elastic properties of the arterial wall. J Physiol 1961; 158: 458-469.

7. Linehan JH, Dawson CA, Rickaby DA, Bronikowski TA. Pulmonary vascular compliance and viscoelasticity. $J$ Appl Physiol 1986; 61: 1802-1814.

8. Greenfield JC, Griggs DM. Relation between pressure and diameter in main pulmonary artery of man. $J \mathrm{Appl}$ Physiol 1963; 18: 557-559.

9. Learyod BM, Taylor MG. Alterations with age in the viscoelastic properties of human arterial walls. Circ Res 1966; 18: 278-292.

10. Hosoda Y, Kawano K, Yamasawa F, Ishii T, Shibata T, Inayama S. Age-dependent changes of collagen and elastin content in human aorta and pulmonary artery. Angiology 1984; 10: 615-621.

11. Gozna ER, Marble AE, Shaw A, Holland JG. Age-related changes in the mechanics of the aorta and pulmonary artery of man. J Appl Physiol 1974; 36: 407-411.

12. Pasierski TJ, Starling RC, Binkley PF, Pearson AC. Echocardiographic evaluation of pulmonary artery distensibility. Chest 1993; 103: 1080-1083. 
13. Hoeks APG, Brands PJ, Smeets FAM, Reneman RS. Assessment of the distensibility of superfacial arteries. Ultrasound Med Biol 1990; 16: 121-128.

14. Bonyhay I, Jokkel G, Karlocai K, Reneman R, Kollai M. Effect of vasoactive drugs on carotid diameter in humans. Am J Physiol 1997; 273: H1629-H1636.

15. Kool MJF, van Merode T, Reneman RS, Hoeks APG, Struyker Boudier HAJ, Van Bortel LMAB. Evaluation of reproducibility of a vessel wall movement detector system for assessment of large artery properties. Cardiovasc Res 1994; 28: 610-614.

16. Bland JM, Altman DG. Statistical methods for assessing agreement between two methods of clinical measurement. Lancet 1986; 8: 307-310.

17. Bogren HG, Klipstein RH, Mohiaddin RH, et al. Pulmonary artery distensibility and blood flow patterns: a magnetic resonance study of normal subjects and of patients with pulmonary arterial hypertension. Am Heart $J$ 1989; 118: 990-999.

18. Zuckerman BD, Orton EC, Stenmark KR, et al. Alteration of the pulsatile load in the high-altitude calf model of pulmonary hypertension. J Appl Physiol 1991; 70: 859868.

19. Bertram CD. Energy dissipation and pulse wave attenuation in the canine carotid artery. J Biomech 1980; 13 : 1061-1073.

20. Kawasaki T, Sasayama S, Yagi S, Asakawa T, Hirai T. Non-invasive assessment of the age related changes in stiffness of major branches of the human arteries. Cardiovasc Res 1987; 21: 678-687.

21. Lanne T, Stale H, Bengtsson $\mathrm{H}$, et al. Noninvasive measurement of diameter changes in the distal abdominal aorta in man. Ultrasound Med Biol 1992; 18: 451-457.

22. Paz R, Mohiaddin H, Longmore DB. Magnetic resonance assessment of the pulmonary arterial trunk anatomy, flow, pulsatility and distensibility. Eur Heart $J$ 1993; 14: 15241530 .
23. Studinger P, Lénárd Zs, Reneman R, Kollai M. Measurement of aortic arch distension wave with echo-track technique. Ultrasound Med Biol 2001; (in press).

24. Angell-James JE, Lumley JSP. The effects of carotid endarterectomy on the mechanical properties of the carotid sinus and carotid sinus nerve activity in atherosclerotic patients. Br J Surg 1974; 61: 805-810.

25. Greenfield JC Jr, Patel DJ. Relation between pressure and diameter in the ascending aorta of man. Circ Res 1962; 10: 778-781.

26. Patel DJ, Schilder DP, Mallos AJ. Mechanical properties and dimensions of the major pulmonary arteries. $J \mathrm{Appl}$ Physiol 1960; 15: 92-96.

27. Slife DM, Latham RD, Sipkema P, Westerhof N. Pulmonary arterial compliance at rest and exercise in normal humans. Am J Physiol 1990; 258: H1823-H1828.

28. Bauer RD, Busse R, Schabert A. Mechanical properties of arteries. Biorheology 1982; 19: 409-424.

29. Fülöp D, Lénárd Zs, Studinger P, Jokkel G, Kollai M. Pressure-diameter relation in the carotid artery during and after dynamic exercise. $J$ Physiol 2000; 526: 146.

30. Boutouyrie P, Boumaza S, Challande P, Lacolley P, Laurent S. Smooth muscle tone and arterial wall viscosity an in vivo/in vitro study. Hypertension 1998; 32: 360364.

31. Reneman RS, Van Merode T, Hick PJJ, Muytjens AMM, Hoeks APG. Age related changes in carotid artery wall properties in men. Ultrasound Med Biol 1986; 12: 465471.

32. Morrell NW, Upton PD, Kotecha S, et al. Angiotensin II activates MAPK and stimulates growth of human pulmonary artery smooth muscle via AT1 receptors. Am J Physiol 1999; 277: L440-L448.

33. Gow BS. The influence of vascular smooth muscle on the viscoelastic behaviour of blood vessels. In: Bergel DH, ed. Cardiovascular Fluid Dynamics. London, Academic Press, 1972; pp. 65-110. 